Thorax, 1977, 32, 743-748

\title{
Delayed non-mycotic false aneurysm of ascending aortic cannulation site
}

\author{
A. S. SOORAE, J. CLELAND, AND H. O'KANE \\ From the Cardiac Surgical Unit, Royal Victoria Hospital, Grosvenor Road, Belfast BT12 6BA, \\ Northern Ireland
}

\begin{abstract}
Soorae, A. S., Cleland, J., and O'Kane, H. (1977). Thorax, 32, 743-748. Delayed non-mycotic false aneurysm of ascending aortic cannulation site. Two cases of delayed non-mycotic false aneurysm arising from the ascending aortic cannulation site, presenting one-and-a-half years and seven years after cardiopulmonary bypass, are described. These two cases represent an incidence of $0 \cdot 12 \%$ of this complication. Repair using profound hypothermia and circulatory arrest with femoral artery and femoral vein cannulation for cardiopulmonary bypass is recommended. The advantages and complications of aortic cannulation are discussed and recommendations to minimise the complications of cannulation are made. The clinical presentation and diagnosis of non-mycotic false aneurysms arising from the aortic cannulation site are described. In addition one delayed and two early cases of non-mycotic cannulation site false aneurysms previously published are analysed. Surgeons should be alert to the possibility of this complication in all patients who have had aortic cannulation for cardiopulmonary bypass even in the distant past. Unexpected symptoms such as constant anterior chest pain, dysphagia, hoarseness, and increasing widening of the superior mediastinum on the chest radiograph warrant prompt investigation.
\end{abstract}

Delayed non-mycotic false aneurysm arising from the ascending aortic cannulation site is a rare complication of this technique for arterial return in cardiopulmonary bypass, and only one case has been reported previously (Williams et al., 1976). We report a further two patients who presented one-and-a-half years and seven years after the original operation.

A total of over 1600 aortic cannulations have been carried out in our unit and the two cases reported here represent an incidence of $0.12 \%$ of this complication.

\section{Case reports}

\section{CASE 1}

A 44-year-old man with a history of rheumatic fever at the age of 9 years had the mitral valve replaced with a size 4 Starr-Edwards cloth-covered prosthesis for mitral stenosis in October 1969 (see Table). Cannulation and decannulation were carried out uneventfully and the sternotomy wound healed satisfactorily. The postoperative progress was uncomplicated and he was discharged from hospital two weeks after the operation.

He was seen regularly in the outpatient department and within six months he was working a 12-hour day on his farm. However, he remained in atrial fibrillation and 10 months later he underwent an unsuccessful attempt at DC cardioversion. During this procedure a small burn was produced over one of the sternal suture wires at the level of the manubriosternal junction, possibly due to inappropriate contact with the electrode. This ultimately resulted in a sinus in which the sternal wire could be easily palpated. This sinus was excised and the sternal wire removed. Histological examination showed a foreign-body reaction with chronic inflammatory cells but culture from the area was sterile.

The patient was readmitted to hospital in February 1971 with a fluctuant swelling in the upper third of the sternotomy scar at the site of the previous sinus. This produced serosanguinous fluid when incised, but no organisms were cultured from the fluid. As he had a low-grade pyrexia, 
Table Details of cases of non-mycotic false aneurysm from ascending aortic cannulation site

\begin{tabular}{|c|c|c|c|c|c|c|}
\hline Author & $\begin{array}{l}\text { Age/sex } \\
\text { of patient }\end{array}$ & Original operation & $\begin{array}{l}\text { Time between } \\
\text { operation and } \\
\text { diagnosis }\end{array}$ & Clinical presentation & Re-operation & Comment \\
\hline Flick et al. (1971) & $\begin{array}{l}7 \text { years } \\
\text { Male }\end{array}$ & $\begin{array}{l}\text { Repair of } \\
\text { membranous } \\
\text { subvalvular } \\
\text { aortic stenosis }\end{array}$ & 5 weeks & $\begin{array}{l}\text { Pulsatile mass in } \\
\text { suprasternal notch. } \\
\text { Chest radiograph- } \\
\text { widening of } \\
\text { superior } \\
\text { mediastinum }\end{array}$ & $\begin{array}{l}\text { Successful repair by } \\
\text { means of peripheral } \\
\text { cannulation, } \\
\text { profound } \\
\text { hypothermia, and } \\
\text { circulatory arrest }\end{array}$ & - \\
\hline Branchini et al. (1976) & $\begin{array}{l}54 \text { years } \\
\text { Male }\end{array}$ & $\begin{array}{l}\text { Mitral valve } \\
\text { replacement }\end{array}$ & 6 weeks & $\begin{array}{l}\text { Pulsatile mass in } \\
\text { upper third of } \\
\text { sternotomy scar. } \\
\text { Chest radiograph- } \\
\text { non-contributory }\end{array}$ & $\begin{array}{l}\text { Repair under limited } \\
\text { cardiopulmonary } \\
\text { bypass and } \\
\text { hypothermic } \\
\text { circulatory arrest }\end{array}$ & $\begin{array}{l}\text { Patient died } 40 \mathrm{~h} \\
\text { later. Necropsy- } \\
\text { posterior myocardial } \\
\text { infarction due to } \\
\text { right coronary artery } \\
\text { injury at operation. } \\
\text { Subarachnoid } \\
\text { haemorrhage }\end{array}$ \\
\hline Williams et al. (1976) & $\begin{array}{l}42 \text { years } \\
\text { Male }\end{array}$ & $\begin{array}{l}\text { Double aorta to } \\
\text { coronary artery } \\
\text { bypass grafts }\end{array}$ & 3 years & $\begin{array}{l}\text { Pulsatile swelling } \\
\text { lower neck, } \\
\text { progressive } \\
\text { dysphagia, and } \\
\text { stridor. Chest } \\
\text { radiograph-density } \\
\text { in upper and } \\
\text { anterior mediastinum }\end{array}$ & $\begin{array}{l}\text { Successful repair } \\
\text { with hypothermia } \\
\text { and circulatory } \\
\text { arrest }\end{array}$ & - \\
\hline $\begin{array}{c}\text { This study } \\
\text { Case } 1\end{array}$ & $\begin{array}{l}44 \text { years } \\
\text { Male }\end{array}$ & $\begin{array}{l}\text { Mitral valve } \\
\text { replacement }\end{array}$ & $1 \frac{1}{2}$ years & $\begin{array}{l}\text { Intermittent sinus } \\
\text { and haemorrhage } \\
\text { from sternotomy } \\
\text { scar. Chest } \\
\text { radiograph- } \\
\text { widening of } \\
\text { superior mediastinum }\end{array}$ & $\begin{array}{l}\text { Successful repair } \\
\text { without the aid of } \\
\text { cardiopulmonary } \\
\text { bypass }\end{array}$ & $\begin{array}{l}\text { Aneurysm ruptured } \\
\text { in anaesthetic room. } \\
\text { Repair without } \\
\text { bypass was possible } \\
\text { because of narrow } \\
\text { neck (Fig. 1) as } \\
\text { bleeding could be } \\
\text { controlled with } \\
\text { finger tip }\end{array}$ \\
\hline Case 2 & $\begin{array}{l}62 \text { years } \\
\text { Female }\end{array}$ & $\begin{array}{l}\text { Mitral valve } \\
\text { replacement }\end{array}$ & 7 years & $\begin{array}{l}\text { Pulsatile swelling in } \\
\text { anterior chest wall, } \\
\text { sternal pain, and } \\
\text { sensation of } \\
\text { hoarseness. Chest } \\
\text { radiograph- } \\
\text { calcification and } \\
\text { widening of } \\
\text { superior mediastinum }\end{array}$ & $\begin{array}{l}\text { Repair using } \\
\text { peripheral } \\
\text { cannulation, } \\
\text { cardiopulmonary } \\
\text { bypass, hypothermia, } \\
\text { and circulatory } \\
\text { arrest }\end{array}$ & $\begin{array}{l}\text { Patient died } 27 \text { days } \\
\text { postoperatively from } \\
\text { progressive } \\
\text { respiratory and } \\
\text { hepatic failure }\end{array}$ \\
\hline
\end{tabular}

blood cultures were made, but no organisms were grown. Intermittent bleeding and serosanguinous discharge from the area slowly diminished, and the patient was allowed to go home. He was readmitted in March 1971 after a large haemorrhage from the same region. He was found to be clinically anaemic, apyrexial, and in atrial fibrillation at 76 per minute and his blood pressure was $110 / 70$ $\mathrm{mmHg}$. Normal prosthetic valve sounds were heard. A chest radiograph showed cardiomegaly with some widening of the superior mediastinum when compared with previous chest radiographs. Tomograms of the sternum suggested osteomyelitis. Exploration of the sinus was carried out and the osteoporotic bone was nibbled away, revealing a pulsatile swelling behind the sternum. At this stage the procedure was terminated. An aortogram performed on the following day showed a false aneurysm arising from the ascending aorta about $2 \mathrm{~cm}$ proximal to the origin of the innominate artery and lying between the aorta and the posterior surface of the sternum (Fig. 1).

He was taken to the operating theatre the next day for repair of the aneurysm. During induction of anaesthesia the aneurysm ruptured, resulting in torrential haemorrhage. The sternum was partially opened without sterile precautions and control of the haemorrhage was obtained by inserting a finger through the neck of the aneurysm, which was about $1 \mathrm{~cm}$ in diameter and situated at the previous cannulation site. The sternal splitting was formally completed while the finger effectively controlled the bleeding. To close the orifice of the aneurysm, sutures buttressed with Teflon strips were passed under the finger and tied, thus controlling the haemorrhage. The sac of the aneurysm was then sutured over the front of the aorta.

No organisms were cultured from the aneurysm after three weeks of incubation and blood cultures before and after operation were all negative. 

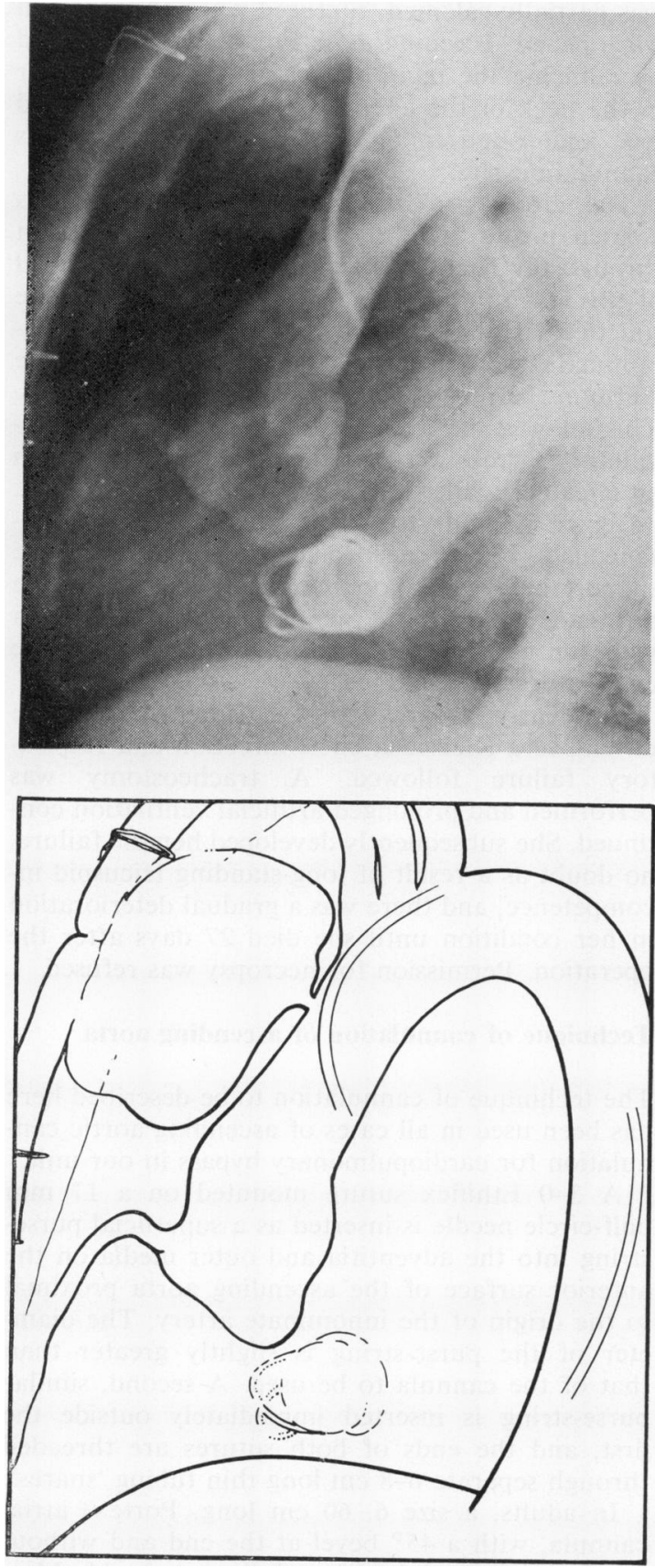

Fig. 1 Case 1. Aortogram, lateral view, showing false aneurysm situated between the posterior surface of the sternum and ascending aorta; note the narrow neck.

His recovery following this near disaster was uneventful, and he is alive and well six years after this episode.

\section{Case 2}

A 55-year-old woman with a history of rheumatic fever at the age of 26 years and a closed mitral valvotomy at 41 years of age was admitted for treatment of re-stenosis of the mitral valve and tricuspid incompetence (see Table). At operation in September 1969 the mitral valve was replaced by a size 3 Starr-Edwards cloth-covered prosthesis. The tricuspid incompetence, which was moderately severe, was thought to be functional and was not corrected. There was no difficulty with cannulation or decannulation of the ascending aorta, nor was there excessive bleeding in the immediate postoperative period, and the sternotomy wound healed by first intention.

The patient's exercise tolerance improved but in the following year she had to be readmitted to hospital on three occasions with congestive heart failure from tricuspid incompetence. The prosthetic valve was functioning normally, but she continued to have signs of marked tricuspid incompetence with an enlarged liver and gross cardiomegaly.

In 1973 cholelithiasis was diagnosed but she was treated conservatively because she was thought to be too ill for surgery. She was readmitted to hospital in August 1976, now aged 62 years, with a year's history of sternal pain, made worse by coughing and movement, and a sensation of hoarseness for two or three months. A week before admission she had noticed a swelling in the front of the chest which was painful and increasing in size. There was no history of dysphagia.

On examination she was in slow atrial fibrillation with equal pulses in both arms and a blood pressure of $135 / 75 \mathrm{mmHg}$. The jugular venous pressure was raised with a large ' $v$ ' wave. The liver was enlarged, and there was clinical evidence of right and left ventricular hypertrophy. Normal prosthetic valve sounds were heard. A pulsatile swelling $6.5 \times 6.0 \mathrm{~cm}$ over the upper third and slightly to the right of the sternotomy scar was visible. A systolic thrill was felt over it and a systolic murmur was heard. The chest radiograph showed gross cardiomegaly with widening and faint calcification in the right side of the superior mediastinum. Cardiac catheterisation showed poor left ventricular function and tricuspid incompetence. An aortogram revealed a jet $2 \mathrm{~cm}$ proximal to the origin of the innominate artery filling a saccular cavity lying anterior and to the right of the ascending aorta. (Fig. 2).

Because of the risk of rupture it was decided to repair the aneurysm despite her poor haemodynamic condition. In September 1976 bypass was 

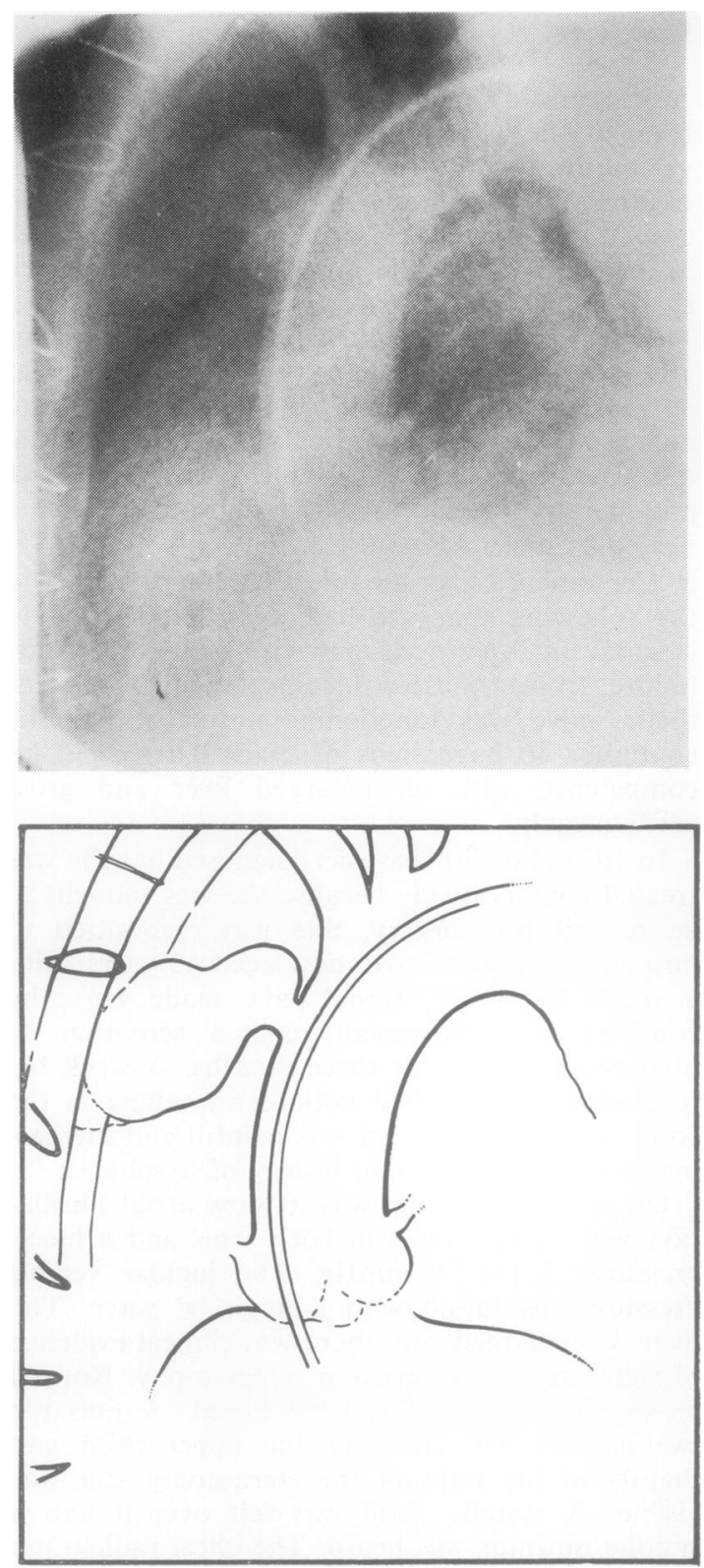

Fig. 2 Case 2. Aortogram, lateral view, showing aneurysm between the sternum and ascending aorta; note the wide neck.

instituted with right femoral artery and vein cannulation and cooling to $22^{\circ} \mathrm{C}$. The artery was cannulated with a size 20 arterial cannula ${ }^{1}$ and the venous cannula was introduced approximately as far as the right atrium. The aneurysm, which

${ }^{1}$ USCI, Division of CR Bard Inc, Ballerica, Massachusetts 01821, USA was partially calcified, ruptured when the sternum was opened. Bleeding at this stage was controlled by reducing the pump flow and inserting a finger in the neck of the aneurysm, which was dissected free and found to be arising from the previous cannulation site.

The circulation was arrested and repair was carried out by direct suture over pledgets of Teflon through the neck of the aneurysm. It was noticed at this stage that a tear had been produced at the junction of the superior vena cava and the innominate vein as a result of retraction of the sternum before adequate freeing of adhesions. This allowed air to enter the venous system. Circulatory arrest was continued for longer than anticipated while the tear was being repaired. After re-warming the heart started to beat spontaneously but it needed considerable inotropic support before cardiopulmonary bypass could be terminated. After the operation the patient soon woke up and the following morning all inotropic drugs were discontinued.

Her early progress was satisfactory but she developed a Klebsiella chest infection and respiratory failure followed. A tracheostomy was performed and prolonged artificial ventilation continued. She subsequently developed hepatic failure, no doubt as a result of long-standing tricuspid incompetence, and there was a gradual deterioration in her condition until she died 27 days after the operation. Permission for necropsy was refused.

\section{Technique of cannulation of ascending aorta}

The technique of cannulation to be described here has been used in all cases of ascending aortic cannulation for cardiopulmonary bypass in our unit.

A 3-0 Ethiflex suture mounted on a $17 \mathrm{~mm}$ half-circle needle is inserted as a superficial pursestring into the adventitia and outer media on the anterior surface of the ascending aorta proximal to the origin of the innominate artery. The diameter of the purse-string is slightly greater than that of the cannula to be used. A second, similar purse-string is inserted immediately outside the first, and the ends of both sutures are threaded through separate $6-8 \mathrm{~cm}$ long thin tubing 'snares'.

In adults, a size $6,60 \mathrm{~cm}$ long, Portex ${ }^{2}$ atrial cannula, with a $45^{\circ}$ bevel at the end and without side holes, is used for cannulation. A double Mersilene suture is applied on the cannula $2-3 \mathrm{~cm}$ from the tip to act as a marker. A polished stainless stee connector is attached to the outer end of the cannula.

A lateral occlusion clamp is applied longitudin- 
ally enclosing the area of the purse-strings and a longitudinal incision slightly smaller than the diameter of the cannula is made with a No. 11 Bard Parker scalpel blade. The aortotomy is inspected to ensure that the incision has not dissected into the wall and the edges are gently held apart with Potts-Smith diamond jaw forceps: as the cannula, held near its tip, is quickly guided along the forceps into the aortic lumen the clamp is released. The cannula is inserted as far as the marker suture, the purse-strings are tightened, and the snares are tied to the cannula thus securing it in position. We think that this technique, in which the cannula is introduced under direct vision and guided into the aortic lumen along the forceps holding the edges of the aorta, prevents the tip of the cannula dissecting into the wall of the aorta.

At the conclusion of perfusion a lateral occlusion clamp is re-applied and the cannula is removed simultaneously. The aortotomy is closed with a continuous 4-0 Prolene stitch in two layers and the purse-strings are tied without tension.

\section{Discussion}

The use of direct cannulation of the ascending aorta for cardiopulmonary bypass has been generally accepted after early reports by Nũnez and Bailey (1959) and DeWall and Levy (1963).

The reported complications of direct cannulation of the ascending aorta include acute aortic dissection (Salama and Blesovsky, 1970; Reinke et al., 1974; Williams et al., 1974), excessive haemorrhage from the cannulation site necessitating re-operation (Gerbode et al., 1968), and carotid hyperperfusion causing fatal brain damage (Kulkarni, 1968; Krous et al., 1973). Some postperfusion deaths, especially in children, may be due to inadequate aortic arch perfusion, as suggested by Parker (1969). Mycotic false aneurysms arising from the aortic cannulation site, secondary to mediastinal infection, have been described (Lillehei et al., 1969; Salama and Blesovsky, 1970), but false aneurysms from this site in the absence of infection are extremely rare and only three reported cases could be found. Two of these three cases presented in the early postoperative period and the third one presented late, as in our two cases reported here (Table). Cannulation site aneurysm can present either in the early postoperative period (Flick et al., 1971; Branchini et al., 1976) or may be delayed for years, as reported by Williams $e t$ al. (1976) and as occurred in our two cases.

The diagnosis of non-mycotic aneurysms from the ascending aortic cannulation site should be suspected if there is a pulsatile mass in the anterior chest wall or lower neck and increasing widening of the superior mediastinum on a chest radiograph. Four out of the five cases reviewed here had these features in common. Other less common features included symptoms caused by pressure of the aneurysm on surrounding structures, such as sternal pain, sternal erosion, progressive stridor, and dysphagia (Table). The bony changes due to pressure on the posterior surface of the sternum led to the mistaken diagnosis of osteomyelitis in case 1. To confirm the diagnosis of a suspected false aneurysm a biplane aortogram is mandatory.

There is no satisfactory explanation of the cause of this complication in our two cases. There were no difficulties with cannulation or decannulation at the original operation, no excessive postoperative bleeding, no mediastinal or wound infection, and the patients were not hypertensive in the immediate or late postoperative period. At the time of re-operation there was no obvious infection in the mediastinum and no organisms could be cultured from the aneurysms. There is, however, a remote possibility that the electrical burn over the sternal suture wire in case 1 , which occurred at the time of cardioversion, also selectively caused a burn over the aorta with resulting aortic wall necrosis and aneurysmal formation. Neither can a satisfactory explanation be given for the previously published cases with the possible exception of the patient of Branchini et al. (1976) in whom difficulty with haemostasis from the cannulation site necessitated the use of extra pledgets of Teflon.

In order to minimise the complications of cannulation we recommend that the aortotomy should be slightly smaller than the diameter of the cannula and in the longitudinal axis of the aorta. The aortotomy should be made inside a superficially placed double purse-string. The cannula should not be inserted for more than $2-3 \mathrm{~cm}$ into the aortic lumen and it should lie free within the aorta, as indicated by adequate arterial line and peripheral arterial pressures. Through-and-through stitches should be used to close the aortotomy, buttressed by Teflon pledgets if necessary, and the purse-strings should not be tied under tension. If the aorta is markedly atheromatous, repeated clamping and unclamping should be avoided. If the aorta is grossly calcified or aneurysmal femoral artery cannulation should be used. Severe hypertension in the immediate postoperative period should be controlled and the systolic blood pressure should not be allowed to exceed $150 \mathrm{mmHg}$.

We consider that repair using femoral artery and femoral vein cannulation, cardiopulmonary bypass, profound hypothermia, and circulatory 
arrest is the best way of treating these aneurysms (Lillehei et al., 1969; Salama and Blesovsky, 1970). The aneurysm in case 1 ruptured in unusual circumstances and no planned procedure could be carried out. It had a narrow neck (Fig. 1), the bleeding could be controlled with a finger, and it was possible to repair it without the aid of bypass. The actual extent of the aneurysm and the size of the neck at operation do not always correlate well with the aortographic appearances, as in our case 2.

The aneurysm frequently ruptures when the sternum is opened (Lillehei et al., 1969; Branchini et al., 1976) and hence adequate cooling should precede sternotomy so that the circulation can be arrested. The patient's blood is drained into the oxygenator, and thus a bloodless operative field is achieved. Injudicious spreading of the sternum is best avoided if damage to the heart and underlying vessels is to be prevented (Lillehei et al., 1969; Branchini et al., 1976). The tear at the junction of the superior vena cava and innominate artery in our case 2 could thus have been avoided. There is a great danger of air being sucked into the aorta, causing fatal air embolism, when the circulation is arrested and the aneurysm is opened. The perfusion pump should be kept turning very slowly in order to maintain a positive pressure in the aorta; this can be combined with a Trendelenburg tilt of the table of about $30^{\circ}$. Direct suction into the aorta should of course be avoided.

Cannulation of the ascending aorta has proved to be a safe and simple technique with an acceptably low incidence of complications, varying from $0 \cdot 11 \%$ (Flick et al., 1971) to $0.5 \%$ (Gerbode et al., 1968). It avoids some of the complications associated with femoral artery cannulation, which have been reported to vary from $1.2 \%$ (Roe and Kelly, 1969) to $5.4 \%$ (Gerbode et al., 1968), that is, much higher than in aortic cannulation. Aortic cannulation allows larger cannulae to be used, which can be of great importance in children (Nũnez and Bailey, 1959), and avoids a second operative field of questionable sterility. The arterial perfusion site is under direct vision all the time and hence early detection and correction of any complication from it is possible.

\section{References}

Branchini, B., Zingone, B., and Vaccari, M. (1976). Ascending aortic false aneurysm following cannulation for perfusion. Thorax, 31, 234-237.
DeWall, R. A., and Levy, M. J. (1963). Direct cannulation of the ascending aorta for open-heart surgery. Journal of Thoracic and Cardiovascular Surgery, 45, 496-499.

Flick, W. F., Hallermann, F. J., Feldt, R. H., and Danielson, G. K. (1971). Aneurysm of aortic cannulation site: successful repair by means of peripheral cannulation, profound hypothermia, and circulatory arrest. Journal of Thoracic and Cardiovascular Surgery, 61, 419-423.

Gerbode, F., Kerth, W. J., Kovacs, G., Sanchez, P. A., and Hill J. D. (1968). Cannulation of the ascending aorta for perfusion during cardiopulmonary bypass. Journal of Cardiovascular Surgery, 9, 293-296.

Krous, H. F., Mansfield, P. B., and Sauvage, L. R. (1973). Carotid artery hyperperfusion during openheart surgery: Report of a case. Journal of Thoracic and Cardiovascular Surgery, 66, 118-121.

Kulkarni, M. G. (1968). A complication of aortic cannulation. Journal of Cardiovascular Surgery, 9, 207208.

Lillehei, C. W., Todd, D. B., Jr., Levey, M. J., and Ellis, R. J. (1969). Partial cardiopulmonary bypass, hypothermia, and total circulatory arrest. A life saving technique for ruptured mycotic aortic aneurysms, ruptured left ventricle and other complicated cardiac pathology. Journal of Thoracic and Cardiovascular Surgery, 58, 530-544.

Nũnez, L. E., and Bailey, C. P. (1959). New method for systemic arterial perfusion in extracorporeal circulation. Journal of Thoracic Surgery, 37, 707-710.

Parker, R. (1969). Aortic cannulation. Thorax, 24, 742-745.

Reinke, R. T., Harris, R. D., Klein, A. J., and Daily, P. O. (1974). Aortoiliac dissection due to aortic cannulation. Annals of Thoracic Surgery, 18, 295299.

Roe, B. B., and Kelly, P. B. (1969). Perfusion through the ascencling aorta: experience with 410 cases. Annals of Thoracic Surgery, 7, 238-241.

Salama, F. D., and Blesovsky, A. (1970). Complications of cannulation of the ascending aorta for open heart surgery. Thorax, 25, 604-607.

Williams, C. D., Suwansirikul, S., and Engelman, R. M. (1974). Thoracic aortic dissection following cannulation for perfusion. Annals of Thoracic Surgery, 18, 300-304.

Williams, G. D., Zimmerman, G. J., Osam, P. N., and Daniel, M. S. (1976). False aneurysm of aortic cannulation site occurring three years postoperatively: successful repair with hypothermia and circulatory arrest. Journal of Cardiovascular Surgery, 17, 266269.

Requests for reprints to: H. O'Kane, BSc, FRCS, MCh, Cardiac Surgical Unit, Royal Victoria Hospital, Belfast BT12 6BA, Northern Ireland. 